\title{
Assessment of Knowledge and Attitudes toward Attention Deficit/Hyperactivity Disorders among Primary Schools' Teachers in AL-Najaf City
}

\author{
Hassam M. Al-Amarei ${ }^{1}$, Saja H. Mohamed ${ }^{2}$ \\ ${ }^{1}$ P.H.D. Student. Psychiatric and Mental Health Nursing, College of Nursing, University of Kufa, Iraq, \\ ${ }^{2}$ Prof., Psychiatric Nursing, College of Nursing, University of Babylon, Iraq
}

\begin{abstract}
Attention deficit/hyperactivity disorder (ADHD) is one of the common emotional, cognitive and behavioral disorder in primary school children and it affects on children socially and academically, welfare . an important role in identify of $\mathrm{AD} / \mathrm{HD}$ due to their daily contact with students in a range of related situations. Basically, elementary school teachers' need to Knowledge and enhance their positive attitude on pupils with ADHD to create a positive learning environment. Consequently, the present investigator made an insight into the aim of the study as follows: to assess teachers' Knowledge and attitude toward pupils with ADHD and to find out the correlation between knowledge of primary school teachers' regarding ADHD. As well as to find out the relationship between the teachers' knowledge and their demographic data. The study was conducted on at governmental primary schools at Al-Najaf City, Iraq. A total of the (10) governmental primary schools selected randomly from total (253) governmental primary schools in Al-Najaf City. A purposive (nonprobability) sample of (70) primary school teachers' were selected from the candidate schools were included in the present study. During the period of $1^{\text {st }}$ September 2018 to $30^{\text {th }}$ May 2019. The data was collected by questionnaire which consisted of two parts, first part consists socio demographic sheet. Second part is about knowledge and attitude which consist of (53) items scale of teachers' knowledge and attitude about children with ADHD . In the present study. Findings revealed a poor in teachers' knowledge of as well as satisfied responses attitude (negative)to pupils with $\mathrm{AD} / \mathrm{HD}$ among elementary school teachers. Fondly the our main findings indicate that there is a significant positive correlation between the teachers' knowledge and the teachers attitude toward children with $\mathrm{AD} / \mathrm{HD}$. And there is a significant relationship between demographic characteristics and do of knowledge for the sample such as: (age,education level, years of experience,main sources of information). Thus, it is recommended for responsible parties to notes the need for greater efforts to provide teacher training specifically in identifying and managing children with ADHD.
\end{abstract}

Keyword: Attention deficit/hyperactivity disorder (ADHD); Teachers; knowledge; Attitude; perception; Primary school.

\section{Introduction}

Early childhood is one of the most important stages of development in a person's life, as the character begins to develop through the child's interaction with the environment. ${ }^{1}$ Mental process(attention), playsan important role in his intellectual development. Some of the children may have a deficit in their attention associated with hyperactivity. This condition may lead to them to do inappropriate behavior, the disorder is characterized by severe difficulties in one or more of the three regions; lack of attention, impulsivity and hyperactivity. ${ }^{2}$ ADHD is one of the most behavioral disorders widespread among students affecting an estimated of $8 \%$ to $12 \%$ of school-aged children and impact roughly 1-2 students in each classroom over United States. ${ }^{3}$ The estimated of ADHD among elementary school children in Baghdad/ Iraq is approximately $10 \%{ }^{4} \mathrm{n}$ another recent study conducted in Najaf/Iraq on several primary school, the prevalence rate among children of school age was approximately $25 \%$ according to teacher reports. ${ }^{5}$ Given 
that school teachers are often the first to notice behavioral difficulties in children, it is surprising that relatively little research has been done with teachers. ${ }^{6}$ According to the Diagnostic and Statistical Manual of Mental Disorders, Fifth Edition (DSM5), major types of AD/HD have been found including mostly ADHD presentation "ADHD-PI", Hyperactivity disorder and attention deficit are often hyperactive, and this type is higher in females than in males," ADHD-PHI", this type we attribute to males is higher than for females and ADHD combined presentation Hyperactivity "ADHD-C", ? Based on these results, the researcher suggested that comprehensive screening for other problems that occur with ADHD is important and treatment profiles should be tailored by comorbidity status and levels of functional impairment in school settings.

\section{Material and Method}

A descriptive analytic study was carried throughout present study to assessment of knowledge and attitudes toward attention deficit/hyperactivity disorders among primary schools' teachers. The study is conducted from $1^{\text {st }}$ September 2018 to $30^{\text {th }}$ May 2019. A purposive (non- probability) sample of (70) primary school teachers' were selected from the candidate schools were included in the present study. The study was conducted on at governmental primary schools in (northern and southern) of Al-Najaf City, Iraq. A total of the (10) governmental primary schools selected randomly from total (253) governmental primary schools in Al-Najaf City. Instruments used in the study are an assessment tools. The data are collected through the use of self administered technique as means for data collection, by using a questionnaire consists of three parts. First part socio-demographic; the second part contains Knowledge of Attention Deficit Disorder Scale -36- items developed by 8 . To measure teachers' knowledge and of perception on ADHD and part three, teachers' attitudes scale (25 -items) is a measure of attitude toward pupil with ADHD developed by ${ }^{9,18}$. The researcher adopted foreword/ backward translation for the study scales (knowledge and attitude), i.e. the English version of the scales are translated into Arabic version and then an experts from the English specialty are selected to translate the Arabic version into an English one and to compare the two versions of English instruments. Some modifications are needed to complete the study instrument as the experts suggestions. After review and evaluation by the experts, reveal that the instrument has adequate content and major changes have been done such as number of alternative become multiple selection questions to all items according to their suggestions. Reliability of the questionnaire is determined through a pilot study and the validity is achieved through a panel of (22) experts. The data was described statistically and analyzed through use of the descriptive and inferential statistical analysis procedures.

\section{Results}

This figure shows that the participants' experience varied from 11-21 years of experience $(38.60 \%, \mathrm{n}=27)$.

\section{Years of Experience}

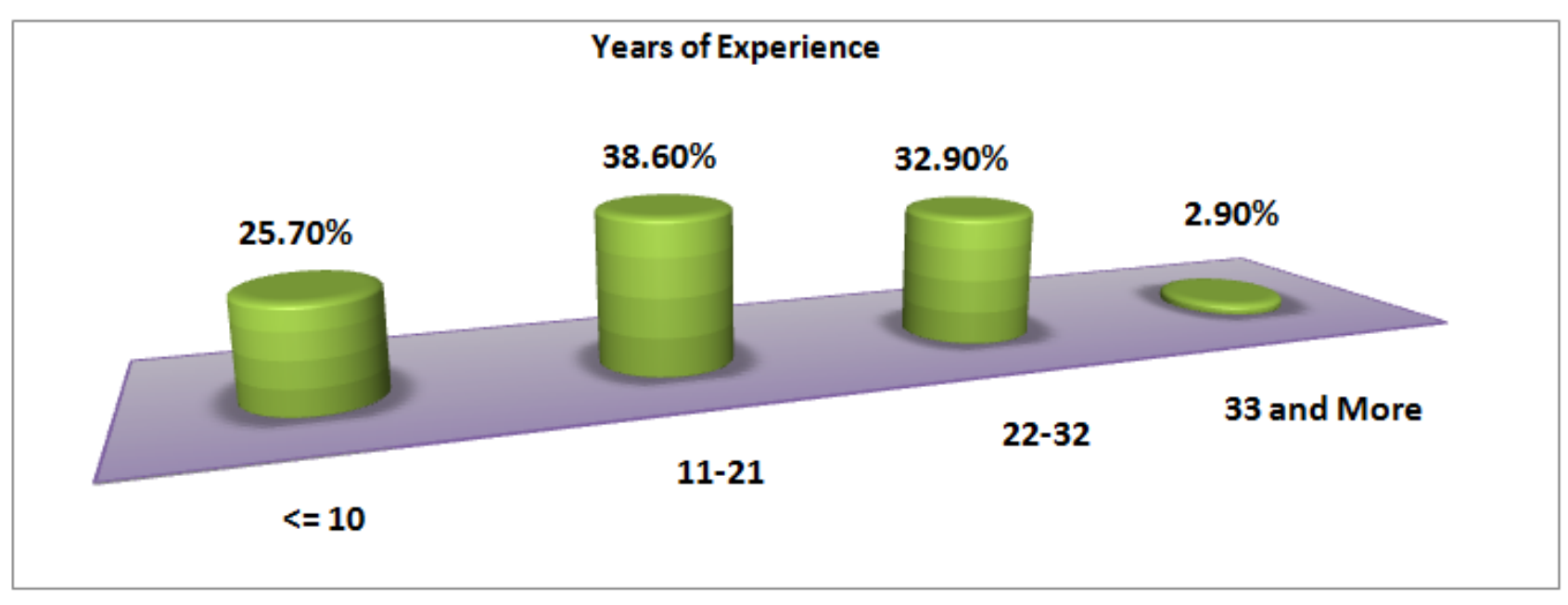

Figure 1. Distribution of the sample of the study according to their experience.

This figure shows that the participants 10 or less years of experience $(38.60 \%)$. 


\section{Source of main information about ADHD}

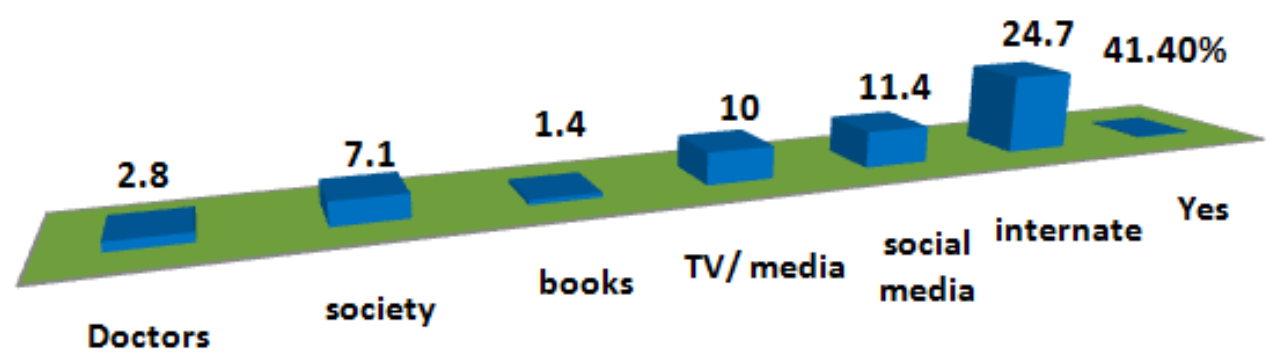

Figure 2. The main source of information about ADHD.

This figure shows that $24.7 \%$ and $(11.4 \%)$, their information obtained from the Internet and social media.

Table (1). Distribution of the sample regarding total Knowledge about ADHD.

\begin{tabular}{|c|c|c|c|c|c|c|c|c|c|}
\hline \multirow{4}{*}{ Knowledge } & \multirow{3}{*}{ No. } & \multicolumn{8}{|c|}{ Levels of teachers' Knowledge } \\
\hline & & \multicolumn{2}{|c|}{ Poor } & \multicolumn{2}{|c|}{ Fair } & \multicolumn{2}{|c|}{ Good } & \multirow[b]{2}{*}{$\mathbf{F}$} & \multirow[b]{2}{*}{$\%$} \\
\hline & & $\mathbf{F}$ & $\%$ & $\mathbf{F}$ & $\%$ & $\mathbf{F}$ & $\%$ & & \\
\hline & 70 & 57 & 81.4 & 11 & 15.7 & 2 & 2.9 & 70 & 100 \\
\hline
\end{tabular}

As shown in Table 1, the vast majority of the sample $81.4 \%$ have poor knowledge about ADHD, whereas $(15.7 \%)$ of them have a fair level of knowledge about ADHD.

Table (2). Distribution of the sample regarding attitude about ADHD

\begin{tabular}{|c|c|c|c|c|c|c|c|c|c|}
\hline \multirow{4}{*}{ Attitude } & \multirow{3}{*}{ No. } & \multicolumn{8}{|c|}{ Levels of teachers' attitude } \\
\hline & & \multicolumn{2}{|c|}{ Satisfied } & \multicolumn{2}{|c|}{ Partially satisfied } & \multicolumn{2}{|c|}{ Dissatisfied } & \multirow[b]{2}{*}{$\mathbf{F}$} & \multirow[b]{2}{*}{$\%$} \\
\hline & & $\mathbf{F}$ & $\%$ & $\mathbf{F}$ & $\%$ & $\mathbf{F}$ & $\%$ & & \\
\hline & 70 & 50 & 71.4 & 13 & 18.6 & 7 & 10 & 70 & 100 \\
\hline
\end{tabular}

The table revealed that $71.4 \%$ have satisfied responses about ADHD, whereas (18.6\%) of them have partially satisfied level .

Table (3). Association between Knowledge Domains and teachers attitude.

\begin{tabular}{|c|c|c|c|c|c|c|}
\hline \multicolumn{2}{|l|}{ Demographic data } & $\begin{array}{c}\text { General } \\
\text { information }\end{array}$ & $\begin{array}{c}\text { Symptom } \\
\text { diagnosis }\end{array}$ & Treatment & $\begin{array}{c}\text { Total } \\
\text { Knowledge }\end{array}$ & Total Attitude \\
\hline \multirow{2}{*}{ General information } & Pearson Corre. & & 0.277 & 0.094 & 0.681 & 0.489 \\
\hline & Sig. & & 0.020 & 0.441 & .000 & .000 \\
\hline \multirow{2}{*}{ Symptom diagnosis } & Pearson Corre. & 0.277 & & 0.331 & 0.771 & 0.231 \\
\hline & Sig. & 0.020 & & 0.005 & 0.000 & 0.055 \\
\hline \multirow{2}{*}{ Treatment } & Pearson Corre. & 0.094 & 0.331 & & 0.643 & 0.249 \\
\hline & Sig. & 0.441 & 0.005 & & 0.000 & 0.038 \\
\hline \multirow{2}{*}{ Total Knowledge } & Pearson Corre. & 0.681 & 0.771 & 0.643 & & 0.468 \\
\hline & Sig. & 0.000 & 0.000 & 0.000 & & 0.0001 \\
\hline
\end{tabular}

This table shows a signified positive correlation between teachers' knowledge and teachers attitude $(\mathrm{r}=0.468$, at $\mathrm{P}$-value $=0.0001)$. 
Table (4). The Relationship between the total teachers' knowledge with respect to their socio-demographic characteristics:

\begin{tabular}{|l|c|c|c|}
\hline Demographic data & Chi-square value & d.f. & p-value \\
\hline Age/years & 11.538 & 4 & $\begin{array}{c}0.021 \\
\mathrm{~S}\end{array}$ \\
\hline Education level & 6.894 & 4 & $\begin{array}{c}9.562 \\
\mathrm{~S}\end{array}$ \\
\hline Years of Experience & 13.592 & 4 & $\begin{array}{c}0.026 \\
\mathrm{~S}\end{array}$ \\
\hline Main Sources of information & 15.659 & 12 & $\begin{array}{c}0.032 \\
\mathrm{~S}\end{array}$ \\
\hline
\end{tabular}

The study results shows a significant association between teachers' knowledge with age,; their education level;years of experience and main Sources of information source information at p-value less than 0.05 .

\section{Discussion}

The carried result revealed most of the teachers were a young age (31-40) years old category. This finding reflect two important approach, one, young teachers' has been found to be challenging for the attentional and meta cognitive capacities of most primary school pupils. This is similar to the results of. ${ }^{10}$ entitled "Effect educational program on elementary school teachers knowledge, attitude and classroom management techniques regards ADHD", who found that the most ages of teachers were at (31-40) years old. The results of this study show that the majority of participants' teaching experience of study sample were at 10 or less years, $(38.6 \%$ ) (Figure $1)$. This result of the study was do not agree with the study ${ }^{11}$, who found more than one third $(46.7 \%)$ of them had more than 15 years teaching experience. Regarding the main sources of acquiring information about ADHD, the present study showed that $24.7 \%$ of teachers acquired knowledge about ADHD from the Internet followed by $11.4 \%$ from social media and $(10 \%)$ from television programs (Figure 2). This result reflects the tremendous availability of information on the internet in this era, however, reliance on the internet as a source of information is not appropriate, as all information available online is not from original sources and when it comes to information about the disease, one must be careful. ${ }^{13}$. (Table 1,2)Distribution of the sample regarding total Knowledge and total attitude about ADHD. The result of the study revealed that most of the participants have poor knowledge and negative satisfied attitude toward pupils with ADHD. Recently, several studies conducted that this result may be due to the teachers not knowing about this disease and how to deal with the child who suffers from it and it cannot appreciate its importance, so the child neglects. Probably, The shortfall in the quality of teacher preparation and standards in Iraq, which makes it difficult in completing the assessment schedules that professionals need in the diagnosis of ADHD, it is necessary to fully know the characteristics and criteria of ADHD as a neurobiological disorder. Several studies. ${ }^{13,12,15}$, found that the study reveals that most of the teachers' had poor knowledge regarding general information of ADHD as well as inadequate knowledge about general information and symptom diagnosis and, treatment, teachers scores on KADDS were poor (knowledge general information domain (57\%); symptom diagnosis domain (59.1\%) and treatment domain $63 \%$ ), pointing to a significant lack of knowledge about ADHD. Second,teachers' level of knowledge of ADHD correlated positively with their level of confidence in teaching a student with ADHD. Third, teachers level of knowledge of ADHD was positively related to their prior training about ADHD. (Table 3). Fondly the our main findings indicate that there is a significant positive correlation between the teachers' knowledge and the teachers attitude $(\mathrm{r}=0.468, \mathrm{P}<0.0001)$. Because teachers with better knowledge, As we expected, the teachers could be less negative attitudes towards ADHD. This result is congruent with a large group of research studies such as the one by ${ }^{13}$, "Knowledge and attitude of male primary school teachers about ADHD in Riyadh, Saudi Arabia”, reported the significant correlation between a teacher's knowledge and attendance of a structured training 
course, attendance of structured training courses affected the teacher's knowledge and attitude toward pupils with ADHD. Moreover ${ }^{6}$ found that there was a significant positive correlation between knowledge and attitude. Also $^{9}$, " Teachers' perception and attitudes toward ADHD in primary school". Their findings indicate that there is a significant correlation between the teachers' knowledge and the teachers attitude $(\mathrm{r}=0.249 \& \mathrm{P}=$ $0.000 *$ ). Table (4). The study results shows a significant association between teachers' knowledge with age,; their education level;years of experience and main Sources of information source information at $\mathrm{p}$-value less than 0.05 . Perhaps, many younger teachers using a new train for knowledge and culture such as I pad and pc computer technology making them more acceptable for education program than older teachers. This result was supported by ${ }^{16}$, "who to the study examines and compares general and special education teachers' knowledge and misconceptions about ADHD. In addition, it seeks to investigate the role of specific demographic variables. They found that "statistically significant relation between teachers' knowledge and their age. The finding of this study contradicts that of ${ }^{11}$, who found that education level of teachers did not have significant influence over their knowledge of ADHD. While the finding of this study asserted that of ${ }^{17}$, who found that the education level of teachers did have a significant influence on the knowledge and attitude of primary school teachers towards pupils with ADHD, teachers' attitudes towards ADHD children are already sufficient because they often meet with their students and know the best way to deal with them. This result agrees with" 18 , after teachers gain classroom experience, the study recommended that knowledge of ADHD develops rather than during their education, classroom experience may evoke greater knowledge of ADHD due to contact with pupils who have ADHD, in-service training on ADHD and information gained from parents, other teachers, or individual study. Conclusion: A poor in teachers' knowledge of as well as satisfied responses attitude (negative)to pupils with $\mathrm{AD} /$ HD among elementary school teachers. Fondly the our main findings indicate that there is a significant positive correlation between the teachers' knowledge and the teachers attitude toward children with $\mathrm{AD} / \mathrm{HD}$. And there is a significant relationship between demographic characteristics and do of knowledge for the sample such as: (age,education level, years of experience, main sources of information). Thus, it is recommended for responsible parties to notes the need for greater efforts to provide teacher training specifically in identifying and managing children with ADHD. At least one, the teachers should participate in a training session about how to dealing with children suffer from ADHD. A mass media approaches should be used in population in order to increasing the teachers' knowledge and enhance their attitude about the ADHD.

Financial Disclosure: There is no financial disclosure.

Conflict of Interest: None to declare.

Ethical Clearance: All experiential protocols were approved under the College of Nursing, University of Babylon. Iraq and all experiments were carried out in accordance with approved guidelines .

\section{References}

1. Gordon, A. M.; Williams Browne, K. Beginning Essentials in Early Childhood Education (3rd edn). Boston, MA: Cengage Learning. Available at gov. uk/government/publications (2015) Final report of the Commission on Assessment without Levels. 2016.

2. Khalil, Amal Ibrahim; ALshareef, Faten Ahmed; ALshumrani, Halemah Ghoneem. Knowledge, Attitude,; Behavioural Practice Elementary Teacher of ADHD Children: Impact of an Educational Intervention. American Journal of Nursing, 2019, 8.6: 329-341.

3. Narad, Megan E., et al. Parent-teacher agreement on ADHD symptoms across development. Psychological assessment, 2015, 27.1: 239.

4. ALOBAIDI, Abdul Kareem Salman; ALI, Numan S. ADHD among schoolchildren in Baghdad. Journal of the Canadian Academy of Child and Adolescent Psychiatry, 2009, 18.1: 4.]

5. AL-FATLAWI, Duaa Abdul Hadi; AL-DUJAILI, Arafat Hussein. Assessment of ADHD among Primary School Children in AL-Najaf City. Indian Journal of Public Health Research \& Development, 2019, 10.1: 1048-1052.

6. Premchand,P.R.(2016)Assess the Knowledge and Attitude of School Teachers Regarding ADHD in Selected School at Gwalior (M.P).International Journal of Science and Research,Volume 7 Issue 1, January 2018.

7. EDITION, Fifth, et al. Diagnostic and statistical manual of mental disorders. Am Psychiatric Assoc, 2013., P.P.45-46. 
8. Sciutto, Mark J.; TERJESEN, Mark D.; FRANK, Allison S. Bender. Teachers' knowledge and misperceptions of ADHD. Psychology in the Schools, 2000, 37.2: 115-122.

9. ALY, Shimaa Elwardany; Mohamed, Fayza; Ahmed, Zamzam. Teachers' perception and attitudes toward ADHDin primary schools at Assiut city. AAMJ, 2015, 13.4: 165-173.

10. ALABD, Asmaa Mohammed Ali; Mesbah, Soha Kamel; ALBOLITEEH, Mohammad. Effect of Educational Program on Elementary School Teachers' Knowledge, Attitude and Classroom Management Techniques Regards ADHD. International Journal of Studies in Nursing, 2018, 3.3: 159 .

11. Shehata, Amal, et al. Effectiveness of structured teaching program on knowledge, attitude and management strategies among teachers of primary school toward children with ADHD . IOSR Journal of Nursing and Health Science, 2016, 5.6: 29-37.

12. Youssef, Marsha K.; Hutchinson, Gerard; Youssef, Farid F. Knowledge of and attitudes toward ADHD among teachers: Insights from a Caribbean nation. Sage Open, 2015, 5.1: 2158244014566761 .

13. ALFAGEER, Hamzah Hassan, et al. Knowledge and attitude of male primary school teachers about attention deficit and hyperactivity disorder in
Riyadh, Saudi Arabia. Journal of Natural Science, Biology and Medicine, 2018, 9.2: 257.

14. LASISI, Dupe, et al. Effect of ADHD training program on the knowledge and attitudes of primary school teachers in Kaduna, North West Nigeria. Child and adolescent psychiatry and mental health, 2017, 11.1: 15.

15. Khademi, Mojgan, et al. Knowledge and attitude of primary school teachers in Tehran/Iran towards ADHD and SLD. Global Journal of Health Science, 2016, 8.12: 141-149.

16. Stampoltzis, Aglaia; Antonopoulou, Katerina. Knowledge and misconceptions about attention ADHD: A comparison of Greek general and special education teachers. International Journal of School \& Educational Psychology, 2013, 1.2: 122-130.

17. Jimoh, M. Knowledge and Attitudes towards Attention Deficit Hyperactivity Disorder among Primary School Teachers in Lagos State, Nigeria. Advances in Life Science and Technology, 2014,23(9)?

18. KOS, Julie Marie. Primary school teachers' knowledge, attitudes and behaviours toward children with ADHD . Melbourne,, Australia: RMIT University, 2004 